\title{
Edición crítica de las Tradiciones peruanas de Ricardo Palma
}

\author{
Pedro Díaz Ortiz \\ Instituto Ricardo Palma/Universidad Ricardo Palma \\ tarmapap@yahoo.es \\ Lima-Perú
}

\section{Resumen}

La publicación de la edición crítica de la Primera y Segunda Serie de las Tradiciones peruanas de Ricardo Palma se llevó a cabo en 2008 y 2019, respectivamente. En nuestro artículo señalamos de qué modo Ricardo Palma fue modificando sus tradiciones en sucesivas ediciones y, como una muestra de esta labor, publicamos la tradición «Una aventura del virreypoeta», que forma parte de la Tercera Serie de las Tradiciones peruanas.

Palabras claves: Ricardo Palma, tradición, edición crítica, serie.

\begin{abstract}
The critical edition of the First and Second Series of Peruvian Traditions by Ricardo Palma was published in 2008 and 2019 respectively. In this article, we emphasize how Ricardo Palma modified his traditions in every edition, and, as a sample of this labor, we publish the tradition Una aventura del virrey-poeta that belongs to the Third Series of Peruvian Traditions.
\end{abstract}

Keywords: Ricardo Palma, tradition, critical edition, series. 


\section{Pedro Díaz Ortiz (Perú)}

Escritor, traductor, editor. Doctor en Letras por la Universidad Nacional Mayor de San Marcos. Past-Decano de la Facultad de Humanidades y Lenguas Modernas de la Universidad Ricardo Palma, Ex Director de la Revista de la Facultad de Humanidades y Lenguas Modernas (URP). Director de la Serie Letras Francesas. Ha publicado, entre otras obras, La estética teatral de Valle-Inclán; Un no rompido sueño; Edición crítica de la Primeria Serie de Tradiciones peruanas, de Ricardo Palma; Albert Camus. Teatro y sociedad, y Gaudeamus. Ha realizado diversas traducciones de poesía francesa, de Blaise Cendrars, Raymond Queneau, Georgette Vallejo y André Coyné, entre otros. 
El año 2008 publicamos la edición crítica de la Primera Serie de las Tradiciones peruanas de Ricardo Palma, conformada por 15 tradiciones (Palma, 2008); en el 2019, la Academia Peruana de la Lengua publicó nuestra edición crítica de la Segunda Serie de las Tradiciones peruanas (Palma, 2019), que contiene 42 tradiciones. En la actualidad, hemos concluido la edición crítica de la Tercera Serie (44 tradiciones), de pronta publicación; y estamos avanzando en la revisión y cotejo de las tradiciones que conforman la Cuarta y la Quinta Serie. El total de las Tradiciones peruanas, distribuidas en diez series, es de 477 tradiciones, según consta en la edición de la editorial Cultura Antártica, 6 volúmenes (Lima, 1951).

La edición crítica de una obra literaria es importante e imprescindible sobre todo en casos como el de las Tradiciones peruanas, debido a las variantes que Ricardo Palma fue introduciendo en sus tradiciones, a medida que iba publicándolas, primero en revistas y luego en libros, tal como mostramos en nuestras ediciones críticas de la Primera y Segunda Serie.

Sobre esta particularidad de cómo Ricardo Palma iba corrigiendo e introduciendo variantes en sus tradiciones a medida que estas se iban publicando en volúmenes, él mismo dice:

El autor, antes de compaginarlas en libros, adoptó el sistema de publicar en los periódicos tradiciones, a medida que iban saliendo de su pluma. Así se daba tiempo para escuchar la voz de críticos imparciales y rectificar errores en que por ignorancia o descuido, pudo incurrir. Apesar (sic) de eso no es poco lo que ha tenido que correjir (sic) en esta nueva edición (1883, p. IV).

Para llevar a cabo la edición crítica de una obra literaria, la condición sine qua non es contar con el texto de su primera publicación para luego cotejarla con la siguiente o siguientes 
versiones, según el caso. En lo que se refiere a las Tradiciones peruanas, estas, en su gran mayoría, fueron publicadas a partir de la década de 1850 en periódicos y revistas, tanto en el Perú como en otros países latinoamericanos y españoles, y luego, como señalamos antes, fueron publicándose en sendos volúmenes. En segundo lugar, es también imprescindible contar con un equipo especializado para realizar la búsqueda hemerográfica y bibliográfica de las fuentes originales en bibliotecas especializadas, y sobre todo para llevar a cabo el cotejo entre el texto de la primera publicación, en revistas o libros, y la siguiente o siguientes versiones en nuevas publicaciones, como es el caso de las Tradiciones peruanas.

Como ejemplo de esta ímproba labor para realizar la edición crítica de las Tradiciones peruanas, citamos el caso de la tradición «Don Dimas de la Tijereta». Esta tradición se publicó por primera vez en La República, Lima, Año I, № 17, domingo 6 de marzo de 1864, pp. 135-136. Se publicó también el año 1864 en La Revista de Buenos Aires, pero en julio de dicho año (RBA, Buenos Aires, Año II, N ${ }^{\circ}$ 15, julio 1864, pp. 465-473). La edición crítica de Julio Ortega (1996) señala erróneamente que «Don Dimas de la Tijereta»: «Aparece por primera vez en 1864 en la Revista de Buenos Aires» (Palma, 1996, p.7). Luego, «Don Dimas de la Tijereta» se integró a la Primera Serie de las Tradiciones Peruanas en 1872, y siguió formando parte de la Primera Serie en las ediciones de 1883, 1891, y, finalmente, en la edición barcelonesa de Montaner y Simón, en 1893, versión que, a partir de entonces, fue admitida como la definitiva por Ricardo Palma. Las variantes más importantes que se produjeron en la tradición «Don Dimas de la Tijereta» desde su publicación en La República (1864) hasta la publicada por Montaner y Simón en 1893, consisten en la adición de coplas, párrafos, refranes, frases y palabras, entre otras. Ver al respecto nuestra edición crítica de la Primera Serie de las Tradiciones Peruanas (Lima, 2008). 

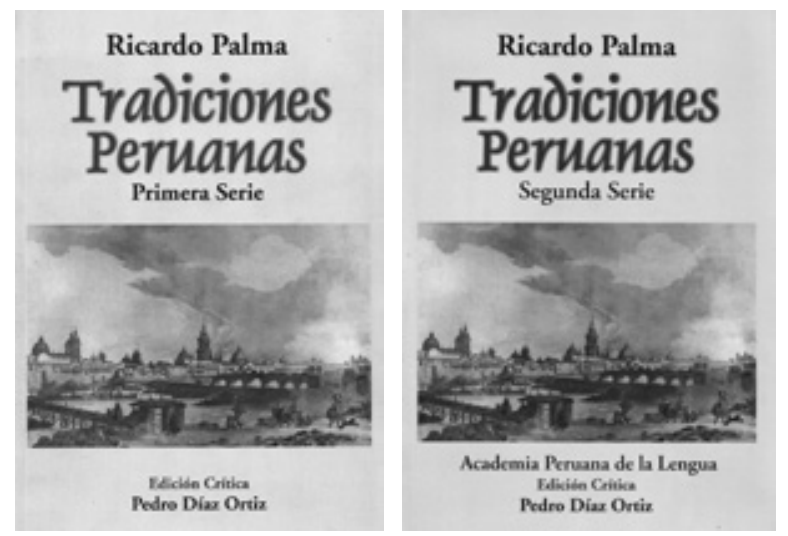

Como muestra de las variantes que Ricardo Palma iba introduciendo en sus tradiciones, a medida que estas se iban publicando en libros, presentamos la tradición «Una aventura del virrey-poeta», que forma parte de la edición crítica de la Tercera Serie de las Tradiciones Peruanas, siguiendo el mismo recurso utilizado en la edición crítica de la Primera y Segunda Serie de las Tradiciones Peruanas: poner en trama, en el texto de la citada tradición, las variantes más importantes con sus respectivas notas a pie de página.

\section{Una aventura del virrey-poeta ${ }^{1}$}

El bando de los vicuñas, llamado así por el sombrero que usaban sus afiliados, llevaba la peor parte en la guerra civil de Potosí. Los vascongados dominaban por el momento, porque el corregidor de la imperial villa, don Rafael Ortiz de Sotomayor, les era completamente adicto.

1 Según lo investigado hasta la fecha, se publicó por primera vez en El Correo del Perú, año V, No VI, domingo 7 de febrero de 1875, pp. 46-47. A partir de la edición de 1875 forma parte de la Tercera Serie de las Tradiciones Peruanas. 
Los vascongados se habían adueñado de Potosí, pues ejercían los principales cargos públicos. De los veinticuatro regidores del Cabildo la mitad eran vascongados, y aun los dos alcaldes ordinarios pertenecían a esa nacionalidad, no embargante expresa prohibición de una real pragmática. Los criollos, castellanos y andaluces formaron alianza para destruir o equilibrar por lo menos el predominio de aquéllos, y tal fué el origen de la lucha ${ }^{2}$ que durante muchos años ensangrentara esa región, y a la que el siempre victorioso general de los vicuñas, don Francisco Castillo, puso término en 1624, casando a su hija doña Eugenia con don Pedro de Oyanume, uno de los principales vascongados.

En 1617 el virrey, príncipe de Esquilache, escribió a Ortiz de Sotomayor una larga carta sobre puntos de gobierno, en la cual, sobre poco más o menos, se leía lo siguiente ${ }^{3}$ : «E catad, mi buen don Rafael, que los bandos potosinos trascienden a rebeldía que es un pasmo, y venida es la hora del rigor extremo y de dar remate a ellos; que toda blandura resultaría en deservicio de su majestad, en agravio de Dios Nuestro Señor y en menosprecio de estos reinos. Así nada tengo que encomendar a la discreción de vuesa merced que, como hombre de guerra, valeroso y mañero, pondrá el cauterio allí donde aparezca la llaga; que con estas cosas de Potosí anda suelto el diablo y cundir puede el escándalo como aceite en pañizuelo. Contésteme vuesa merced que ha puesto buen término a las turbulencias y no de otra guisa; que ya es tiempo de que esas parcialidades hayan fin antes que, cobrando aliento, sean en estas Indias otro tanto que los comuneros en Castilla».

2 En El Correo del Perú y en la edición de 1875 dice: [y tal fue la lucha]; a partir de la edición de 1883: [y tal fue el origen de la lucha].

3 En El Correo del Perú y en la edición de 1875 dice: [en la cual se leía lo siguiente]; a partir de la edición de 1883: [en la cual, sobre poco o más o menos, se leía lo siguiente]. 
Los vicuñas se habían juramentado a no permitir que sus hijas o hermanas casasen con vascongados; y uno de éstos, a cuya noticia llegó el formal compromiso del bando enemigo, dijo en plena plaza de Potosí: - Pues de buen grado no quieren ser nuestras las vicuñitas, hombres somos para conquistarlas con la punta de la espada.- Esta baladronada exaltó más los odios ${ }^{4}$, y hubo batalla diaria en las calles de Potosí.

No era Ortiz de Sotomayor hombre para conciliar los ánimos. Partidario de los vascongados, creyó que la carta del virrey lo autorizaba para cometer una barrabasada; y una noche hizo apresar, secreta y traidoramente, a don Alfonso ${ }^{5}$ Yáñez y a ocho o diez de los principales vicuñas, mandándoles dar muerte y poner sus cabezas en el rollo.

Cuando al amanecer se encontraron los vicuñas con este horrible espectáculo, la emprendieron a cuchilladas con las gentes del corregidor, quien tuvo que tomar asilo en una iglesia. Mas recelando la justa venganza de sus enemigos, montó a caballo y vínose a Lima, propalando antes que no había hecho sino cumplir al pie de la letra instrucciones del virrey, lo que como hemos visto no era verdad, pues su excelencia no lo autorizaba en su carta para decapitar a nadie sin sentencia previa.

Tras de Ortiz de Sotomayor viniéronse a Lima muchos de los vicuñas.

\section{II}

Celebrábase en Lima el Jueves Santo del año de 1618 con toda la solemnidad propia de aquel ascético siglo. Su excelencia don Francisco de Borja y Aragón, príncipe de Esquilache, con una

4 En El Correo del Perú dice: [los ánimos]; a partir de la edición de 1875: [los odios].

5 En El Correo del Perú y en las ediciones de 1875 y 1883 dice: [Alonso]; a partir de la edición de 1894: [Alfonso]. 
lujosa comitiva, salió de palacio a visitar siete de las principales iglesias de la ciudad.

Cuando se retiraba de Santo Domingo ${ }^{6}$, después de rezar la primera estación tan devotamente cual cumplía a un deudo de San Francisco de Borja, duque de Gandía, encontróse con una bellísima dama seguida de una esclava que llevaba la indispensable alfombrilla. La dama clavó en el virrey una de esas miradas que despiden magnéticos efluvios, y don Francisco, sonriendo ligeramente, la miró también con fijeza, llevándose la mano al corazón, como para decir a la joven que el dardo había llegado a su destino.

$$
\begin{aligned}
& \text { A la mar, por ser honda } \\
& \text { se van los ríos, } \\
& \text { y detrás de tus ojos } \\
& \text { se van los míos }
\end{aligned}
$$

Era su excelencia muy gran galanteador, y mucho se hablaba en Lima de sus buenas fortunas amorosas. A una arrogantísima figura y a un aire marcial y desenvuelto unía el vigor del hombre en la plenitud de la vida, pues el de Esquilache apenas frisaba en los treinta y cinco años. Con una imaginación ardiente, donairoso en la expresión, valiente hasta la temeridad, y generoso hasta rayar en el derroche, era don Francisco de Borja y Aragón el tipo más cabal de aquellos caballerosos hidalgos que se hacían matar por su rey y por su dama.

Hay cariños históricos, y en cuanto a mí confieso que me lo inspira y muy entusiasta el virrey-poeta, doblemente noble por sus heredados pergaminos de familia y por los que él borroneara

\footnotetext{
6 En El Correo del Perú y en la edición de 1875 dice: [de la catedral]; a partir de la edición de 1883: [de Santo Domingo].

7 La copla señalada con trama no figura en El Correo del Perú ni en las ediciones de 1875 y 1883, fue añadida a partir de la edición de 1894 .
} 
con su elegante pluma de prosador y de hijo mimado de las musas. Cierto es que acordó en su gobierno demasiada influencia a los jesuitas; pero hay que tener en cuenta que el descendiente de un general de la Compañía, canonizado por Roma, mal podía estar exento de preocupaciones de raza. Si en ello pecaba, la culpa era de su siglo, y no se puede exigir de los hombres que sean superiores a la época en que les cupo en suerte vivir.

En las demás iglesias, el virrey encontró siempre al paso a la dama y se repitió cautelosamente el mismo cambio de sonrisas y miradas.

\author{
Por Dios, si no me quieres \\ que no me mires; \\ ya que no me rescates, \\ no me cautives ${ }^{8}$.
}

En la última estación, cuando un paje iba a colocar sobre el escabel un cojinillo de terciopelo carmesí con flecadura de oro, el de Esquilache, inclinándose hacia él, le dijo rápidamente:

-Jeromillo, tras de aquella pilastra hay caza mayor. Sigue la pista.

Parece que Jeromillo era diestro en cacerías tales, y que en él se juntaban olfato de perdiguero y ligereza de halcón; pues cuando su excelencia, de regreso a palacio, despidió la comitiva, ya lo esperaba el paje en su camarín.

-Y bien, Mercurio, ¿quién es ella? —le dijo el virrey, que, como todos los poetas de su siglo, era aficionado a la mitología.

8 La copla señalada con trama no figura en El Correo del Perú ni en las ediciones de 1875 y 1883, fue añadida a partir de la edición de 1894. 
-Este papel, que trasciende a sahumerio, se lo dirá a vuecencia — contestó el paje, sacando del bolsillo una carta.

—iPor Santiago de Compostela! ¿Billetico tenemos? iAh, galopín! Vales más de lo que pesas, y tengo de inmortalizarte en unas octavas reales que dejen atrás a mi poema de Nápoles.

Y acercándose a una lamparilla, leyó:

Siendo el galán cortesano y de un santo descendiente, que haya ayunado es corriente como cumple a un buen cristiano.

Pues besar quiere mi mano, según su fina expresión, le acuerdo tal pretensión, si es que a más no se propasa, y honrada estará mi casa si viene a hacer colación.

La misteriosa dama sabía bien que iba a habérselas con un poeta, y para más impresionarlo recurrió al lenguaje de Apolo.

—iHola, hola! —murmuró don Francisco-, Marisabidilla es la niña; como quien dice, Minerva encarnada en Venus. Jeromillo, estamos de aventura. Mi capa, y dame las señas del Olimpo de esa diosa.

Media hora después el virrey, recatándose en el embozo, se dirigía a casa de la dama.

\section{III}

Doña Leonor de Vasconcelos, bellísima española y viuda de Alonso Yáñez, el decapitado por el corregidor de Potosí, había 
venido a Lima resuelta a vengar a su marido, y ella era la que, tan mañosamente y poniendo en juego la artillería de Cupido, atraía a su casa al virrey del Perú . Para doña Leonor era el príncipe de Esquilache el verdadero matador de su esposo.

Habitaba la viuda de Alonso Yáñez una casa con fondo al río en la calle de Polvos Azules, circunstancia que, unida a frecuente ruido de pasos varoniles en el patio e interior de la casa, despertó cierta alarma en el espíritu del aventurero galán.

Llevaba ya don Francisco media hora de ceremoniosa plática con la dama, cuando ésta le reveló su nombre y condición, procurando traer la conferencia al campo de las explicaciones sobre los sucesos de Potosí; pero el astuto príncipe esquivaba el tema, lanzándose por los vericuetos de la palabrería amorosa.

Un hombre tan avisado como el de Esquilache no necesitaba de más para comprender que se le había tendido una celada, y estaba en una casa que probablemente era por esa noche el cuartel general de los vicuñas, de cuya animosidad contra su persona tenía ya algunos barruntos.

Llegó el momento de dirigirse al comedor para tomar la colación prometida. Consistía ella en ese agradable revoltijo de frutas que los limeños llamamos ante, en tres o cuatro conservas preparadas por las monjas, y en el clásico pan de dulce. Al sentarse a la mesa cogió el virrey una garrafa de cristal de Venecia que contenía un delicioso Málaga, y dijo:

-Siento, doña Leonor, no honrar tan excelente Málaga, porque tengo hecho voto de no beber otro vino que un soberbio pajarate, producto de mis viñas en España.

9 En El Correo del Perú y en la edición de 1875 dice: [tan mañosamente atraía a su casa al virrey del Perú]; a partir de la edición de 1883: [tan mañosamente, y poniendo en juego la artillería de Cupido, atraía a su casa al virrey del Perú]. 
-Por mí no se prive el señor virrey de satisfacer su gusto. Fácil es enviar uno de mis criados donde el mayordomo de vuecencia.

-Adivina vuesa merced, mi gentil amiga, el propósito que tengo. Y volviéndose a un criado le dijo:

-Mira, tunante. Llégate a palacio, pregunta por mi paje Jeromillo, dale esta llavecita, y dile que me traiga las dos botellas de pajarete que encontrará en la alacena de mi dormitorio. No olvides el recado, y guárdate esa onza para pan de dulce.

El criado salió, prosiguiendo el de Esquilache con aire festivo:

-Tan exquisito es mi vino, que tengo que encerrarlo en mi propio cuarto; pues el bellaco de mi secretario Estúñiga tiene, en lo de catar, propensión de mosquito, e inclinación a escribano en no dejar botella de la que no se empeñe en dar fe. Y ello ha de acabar en que me amosque un día y le rebane las orejas para escarmiento de borrachos.

El virrey fiaba su salvación a la vivacidad de Jeromillo y no desmayaba en locuacidad y galantería. Para librarse de lazos, antes cabeza que brazos, dice el refrán ${ }^{10}$.

Cuando Jeromillo, que no era ningún necio de encapillar ${ }^{11}$, recibió el recado, no necesitó de más apuntes para sacar en limpio que el príncipe de Esquilache corría grave peligro. La alacena del dormitorio no encerraba más que dos pistoletes con incrustaciones de oro, verdadera alhaja regia que Felipe III había regalado a don Francisco el día en que éste se despidiera del monarca para venir a América.

10 El refrán señalado con trama no figura en El Correo del Perú ni en la edición de 1875, fue añadido a partir de la edición de 1883.

11 En El Correo del Perú y en la edición de 1875 dice: [Cuando Geromillo recibió el recado]; a partir de la edición de 1883: [Cuando Jeromillo, que no era ningún necio de encapillar, recibió el recado]. 
El paje hizo arrestar al criado de doña Leonor, y por algunas palabras que se le escaparon al fámulo en medio de la sorpresa, acabó Jeromillo de persuadirse que era urgente volar en socorro de su excelencia.

Por fortuna, la casa de la aventura sólo distaba una cuadra del palacio; y pocos minutos después el capitán de la escolta con un piquete de alabarderos sorprendía a seis de los vicuñas conjurados para matar al virrey o para arrancarle por la fuerza alguna concesión en daño de los vascongados.

Don Francisco, con su burlona sonrisa, dijo a la dama:

- Señora mía, las mallas de vuestra red eran de seda y no extrañéis que el león las haya roto. iLástima es que no hayamos hecho hasta el fin vos el papel de Judith, y yo el de Holofernes!

Y volviéndose al capitán de la escolta, añadió:

—Don Jaime, dejad en libertad a esos hombres, y icuenta con que se divulgue el lance y ande mi nombre en lenguas! Y vos, señora mía, no me toméis por un felón, y honrad más al príncipe de Esquilache, que os jura, por los cuarteles de su escudo, que si ordenó reprimir con las armas de la ley los escándalos de Potosí, no autorizó a nadie para cortar cabezas que no estaban sentenciadas.

\section{IV}

Un mes después doña Leonor y los vicuñas volvían a tomar el camino de Potosí; pero la misma noche en que abandonaron Lima, una ronda encontró en una calleja el cuerpo de Ortiz de Sotomayor con un puñal clavado en el pecho ${ }^{12}$.

12 En El Correo del Perú, al final de la tradición figura el nombre del tradicionista: [Ricardo Palma] y la fecha: [Lima, Enero 10 de 1875]. Estos datos fueron eliminados a partir de la edición de 1875. 


\section{Referencias bibliográficas}

Palma, R. (1883). Tradiciones. Primera Serie. Lima: Imprenta del Universo, de Carlos Prince.

. (1996). Tradiciones Peruanas. Edición Crítica. Julio Ortega, Flor María Rodríguez-Arenas (coordinadores) (Segunda ed.). Madrid: Ediciones Unesco, Allca XX, Fondo de Cultura Económica.

. (2008). Tradiciones Peruanas. Primera Serie. Edición crítica de Pedro Díaz Ortiz. Lima: Ed. Pedro Díaz Ortiz.

. (2019). Tradiciones Peruanas. Segunda Serie. Edición Crítica de Pedro Díaz Ortiz. Lima: Ed. Academia Peruana de la Lengua.

Recibido el 11 de septiembre de 2020 Aceptado el 15 de octubre de 2020 